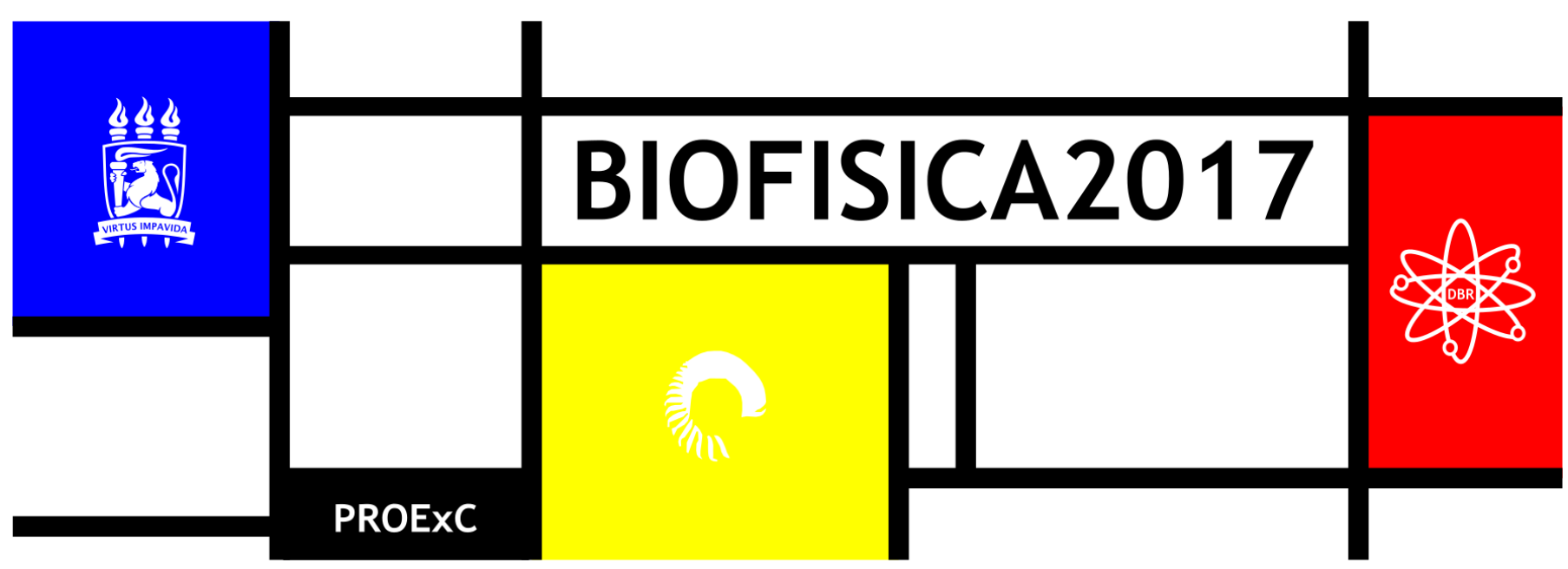

\title{
FREQUÊNCIA DE MICRONÚCLEOS EM PACIENTES PORTADORAS DE CÂNCER DE COLO UTERINO COM INDICAÇÃO A RADIOTERAPIA
}

\author{
Cátia Simone Ferreira Silva ${ }^{1,2 *}$, Mariana Brayner Cavalcanti ${ }^{2}$, Ademir Amaral ${ }^{2}$, Thiago de Salazar e Fernandes ${ }^{2,3}$, \\ Edvane Borges da Silva ${ }^{1,2}$ \\ ${ }^{1}$ Centro Acadêmico de Vitória - UFPE, ${ }^{2}$ Grupo de estudo em radioproteção e radioecologia DEN - UFPE, ${ }^{3}$ Departamento de Biofísica e \\ Radiobiologia. \\ *catia.fsilva@ufpe.br
}

\section{INTRODUÇÃO}

O câncer de colo de útero é uma neoplasia maligna que tem como principal causa a infecção pelo Papiloma Vírus Humano (HPV) (INCA, 2015). Entre os principais tratamentos para o câncer do colo uterino podemos citar a radioterapia, uma modalidade que utiliza a radiação ionizante com o objetivo de eliminar células cancerígenas. No entanto, essa modalidade terapêutica possuí limitação, é a irradiação dos tecidos sadios adjacentes ao tumor e que pode ocasionar efeitos adversos exacerbados, estando esses relacionados com a radiossensibilidade individual. A radiossensibilidade é descrita como uma característica intrínseca, a qual está diretamente ligada aos efeitos adversos exacerbados após a exposição à radiação ionizante (SILVA, et al., 2014). A identificação desses pacientes radiossensivéis pode vir a ser um benefício para o tratamento, por meio da identificação prévia da radiossensibilidade. Um biomarcador sensível, com baixo custo, fácil treinamento e resultado rápido é o teste de micronúcleos, capaz de avaliar a exposição a substâncias potencialmente genotóxicas e instabilidades genéticas (BEIRUTHY, KAZAN, 2016). Diante disso, o presente estudo teve como objetivo avaliar in vitro a frequência de micronúcleos em amostras, irradiadas e não irradiadas, de sangue periférico de pacientes diagnosticadas com câncer de colo uterino com indicação a radioterapia.

\section{MATERIAIS E MÉTODOS}

Aspectos éticos e população estudada

O estudo realizado foi aprovado pelo Comitê de Ética em Pesquisa do Centro de Ciências da Saúde da Universidade Federal de Pernambuco sob parecer de número 1.737.624. Antes do início do experimento, todos os indivíduos assinaram o Termo de Consentimento Livre e Esclarecido (TCLE).

O presente estudo incluiu mulheres com diagnóstico histopatológico de câncer de colo uterino em tratamento radioterápico, que foram atendidas em serviço especializado no Centro de Radioterapia de Pernambuco - CERAPE, do Hospital do Câncer de Pernambuco.
Coleta e irradiação do material biológico

As amostras de sangue ( $9 \mathrm{~mL}$ por indivíduo) foram coletadas de pacientes voluntários $(\mathrm{N}=10)$, utilizando coletor (seringa) para sangue e tubo contendo heparina sódica. A coleta da amostra foi realizada antes do início da radioterapia. Uma parte da amostra foi separada em seringas, para a irradiação in vitro. As seringas foram acondicionadas em um fantoma, construído com um material de densidade semelhante à do tecido mole humano $(\rho=1,0 \mathrm{~g} / \mathrm{cm} 3)$. 0 material foi levado a um acelerador linear (Siemens/ Modelo Primus), pertencente ao Instituto Materno Infantil de Pernambuco IMIP, para serem irradiadas com raios-X de energia de $6 \mathrm{MeV}$, por 2 minutos. Após a irradiação, as amostras foram encaminhadas ao Laboratório de Modelagem e Biodosimetria Aplicada (LAMBDA/GERAR), para a realização do cultivo celular e confecção de lâminas para visualização de micronúcleos.

\section{Cultivo celular}

O cultivo celular para micronúcleos seguiu o método descrito por Fenech (1985) e adaptado pela Agência Internacional de Energia Atômica (IAEA), (2011). Foram utilizados $4 \mathrm{~mL}$ de meio de cultura RPMI 1640 (suplementado com 20\% (1 mL) de soro fetal bovino e $2 \%$ $(0,1 \mathrm{~mL})$ de fitohemaglutinina, para estimular a divisão celular. Em seguida, foram adicionados $0,4 \mathrm{~mL}$ de sangue total. A cultura foi incubada em estufa de $\mathrm{CO} 2(5 \%)$ a $37^{\circ} \mathrm{C}$ por 72 horas. Após transcorridas 44 horas de incubação, foram adicionados $0,2 \mathrm{~mL}$ à cultura citocalasina $B$, numa concentração final de $5 \mathrm{pg} / \mathrm{mL}$, para a obtenção de células linfocitárias binucleadas.

\section{Retirada da cultura e preparo das lâminas}

Após completar 72 horas de incubação da cultura de linfócitos, o material foi transferido para um tubo afunilado para ser centrifugado a $300 \mathrm{~g}$ por 5 minutos. Em seguida, o sobrenadante foi desprezado, sendo realizada a lavagem do sedimento com $7 \mathrm{~mL}$ de solução de $\mathrm{NaCl}(0,9 \%)$ gelado. Posteriormente, foi adicionado $1 \mathrm{~mL}$ de fixador, que consiste em metanol e ácido acético na proporção de 3:1. O material passou por algumas centrifugações até que o sobrenadante estivesse visivelmente límpido. As células foram 
ressuspendidas com cerca de $1 \mathrm{~mL}$ do fixador. Para o preparo das lâminas, foram gotejadas de 2 a 4 gotas da suspensão de células por lâmina devidamente identificadas e as mesmas foram coradas com Giemsa. A lâmina corada foi analisada ao microscópio óptico na objetiva de aumento de 20X, para a observação de células binucleadas, sendo quantificadas 1000 células binucleadas de cada indivíduo (FENECH, 2007), totalizando 54677 células analisadas. As análises dos micronúcleos ocorreram em objetiva de aumento de 100X, em um microscópio biológico modelo E 100, marca NIKON.

\section{Análise estatística}

As variáveis qualitativas foram expressas por frequências absolutas e relativas, enquanto as variáveis quantitativas foram expressas por médias e desvio padrão. Para avaliar a normalidade dos dados obtidos, foi empregado o teste D'Agostino. Para se avaliar a correlação entre as frequências de micronúcleos e os efeitos adversos observados, foi utilizado o teste de Correlação de Pearson (MORETTIN, BUSSAB, 2010). Foi adotado o nível de significância de $5 \%$ (cinco por cento), sendo as análises realizadas por meio do programa BioEstat, versão 5.0 (BRAGANÇA-PEREIRA, 1991).

\section{RESULTADOS E DISCUSSÃO}

Todas as 10 voluntárias (identificadas por P1 a P10), com idades entre 23 - 78 anos. Todas receberam radioterapia pélvica externa adjuvante através de uma máquina de acelerador linear e em alguns casos foi necessária a complementação com a braquiterapia. A paciente $\mathrm{P} 5$ apresentou a maior frequência de micronúcleos pós exposição ao tratamento radioterápico, havendo queixas com efeitos adversos graves. Na (Tabela 1) há a frequência média de micronúcleos antes e após a irradiação. Na (Figura 1) é possível verificar que a paciente P5 apresentou micronúcleos numa frequência maior de dicêntricos após a exposição à radiação ionizante

Tabela 1. Frequência média de micronúcleos em 1000 células binucleadas de linfócitos (Espontânea e irradiada).

\begin{tabular}{ccc} 
linfócitos (Espontânea e irradiada). & \\
\hline Pacientes & $\begin{array}{c}\text { Frequência espontânea } \\
\text { de micronúcleos (\%) }\end{array}$ & $\begin{array}{c}\text { Frequência de } \\
\text { micronúcleos irradiados } \\
\text { (\%) }\end{array}$ \\
\hline P1 & 3,5 & 8,5 \\
P2 & 3 & 6 \\
P3 & 3,5 & 6,5 \\
P4 & 3,5 & 7,5 \\
P5 & 7,5 & 13,5 \\
P6 & 6 & 9 \\
P7 & 5,5 & 8 \\
P8 & 1 & 5,5 \\
P9 & 3,5 & 7,5 \\
P10 & 4,5 & 9 \\
\hline
\end{tabular}
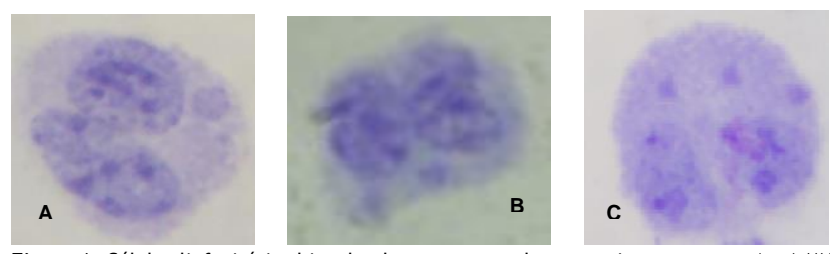

Figura 1. Células linfocitárias binucleadas apresentando respectivamente em: A - 1 MN, B 2 MN e C - 3 MN da paciente P 5 (FONTE: Próprio autor).

Os presentes resultados indicam que a frequência de micronúcleos em indivíduos não irradiados em 1000 células binucleadas variam de $(1-7,5)$. Esses resultados mostram-se compatíveis com a literatura, sendo esperadas uma frequência que varia de $(1-3)$ (CARRARD et al., 2007).

Outros trabalhos afirmam que, há variabilidade da frequência de micronúcleos ocorrida no grupo controle até as amostras irradiadas. Deste modo, o aparecimento de MN pode também estar relacionado a exposições a diversos agente genotóxicos e a falha na capacidade de reparação celular (WIDEL, et al., 2003). A ocorrência de exposições aos mais diversos agentes clastogênicos e/ou genotóxicos, tais como: poluentes e aos raios UV são descritos como potenciais causadores de modificadores do DNA. (DEMIRCIGIL, et al., 2014).

Contudo, a pesquisa mostra que, por meio do teste de micronúcleos é possível a correlação do aumento da sua frequência de micronúcleos em células linfocitárias de amostras sanguíneas irradiada in vitro de pacientes com câncer de colo uterino, podendo vir a ser um benefício para o tratamento, por meio da identificação prévia da radiossensibilidade.

\section{CONCLUSÕES}

Houve um aumento na frequência de micronúcleos nas amostras irradiadas. No entanto, são necessários estudos posteriores, com um maior número de voluntárias para que a hipótese seja confirmada.

\section{REFERÊNCIAS}

BRAGANÇA-PEREIRA, C.A. Teste estatístico para comparar proporções em problemas citogenéticos. In: RABELLO-GAY, M.N.; RODRIGUES, M.A.L.A.R.; MONTELEONE NETO, R. Mutagênese, carcinogênese e teratogênese: Métodos e critérios de avaliação. São Paulo: Sociedade Brasileira de Genética, p. 113-21, 1991.

BEIRUTHY, I.W.; KAZAN, R.S., Étude corrélationnelle sur les facteurs prédictifs de la pratique du test de dépistage du cancer du col utérin chez les femmes fréquentant les centres médico-sociaux à Zahlé (Liban). Revue Francophone Internationale de Recherche Infirmière, v. 2, n. 1, p. 31-40, 2016.

CARRARD, V.C. et al., Teste dos micronúcleos- Um biomarcador de dano genotóxico em células descamadas da mucosa bucal. Rev. Fac. Odontol., Porto Alegre, v.48, n.1-3, p.77 - 81, 2007.

DEMIRCIGIL, G.Ç., et al., Cytogenetic biomonitoring of primary school children exposed to air pollutants: micronuclei analysis of buccal epithelial cells. Environmental Science and Pollution Research, v. 21, n. 2, p. 1197-1207, 2014.

FENECH M.; MORLEY A.A., Measurement of micronuclei in lymphocytes. Mutat. Res., Amsterdam, v.147, n.1-2 p.29-36, 1985. FENECH, M., Cytokinesis-block micronucleus cytome assay. Nature protocols, v. 2, n. 5, p. 1084-1104, 2007.

INTERNATIONAL ATOMIC ENERGY AGENCY (IAEA). Cytogenetic dosimetry: Applications in preparedness for and response to radiation emergercies. Scientific and Technical Publications. Vienna, 2011.

MINISTÉRIO DA SAÚDE, INSTITUTO NACIONAL DE CÂNCER. Colo do útero. Disponível em: http://www2.inca.gov.br/wps/wcm/connect/tiposdecancer/site/h ome/colo_utero/hpv-cancer-perguntas-mais-frequentes >. Acesso em: 20 de out. 2016.

MORETTIN, P. A., BUSSAB, W.O. Estatística Básica 6. Ed. Ed. Saraiva, 2010.

WIDEL, M.; JEDRUS, S.; LUKASZCZYK, B.; RACZEK-ZWIERZYCKA, K.; SWIEMIAK, A. Radiation-induced micronucleus frequency in peripheral blood lymphocytes is correlated with normal tissue damage in patients with cervical carcinoma undergoing radiotherapy. Radiat Res; v. 159, n. J6, p. 713-21, 2003. 